6 OPEN ACCESS

- Additional material is published online only. To view please visit the journal online (http://dx.doi.org/10.1136/ tobaccocontrol-2018-054601).

\section{Correspondence to}

Professor Stanton A Glantz, Department of Medicine, Center for Tobacco Control Research and Education, Cardiovascular Research Institute, Philip R. Lee Institute for Health Policy Studies, Helen Diller Family Comprehensive Cancer Center University of California, San Francisco, San Francisco, CA 94143-1390, USA; glantz@medicine.ucsf.edu

Check for updates

(C) Author(s) (or their employer(s)) 2018. Re-use permitted under CC BY-NC. No commercial re-use. See rights and permissions. Published by BMJ.

To cite: Glantz SA

Tob Control 2018;27:s1-s6.

\title{
Heated tobacco products: the example of IQOS
}

\author{
Stanton A Glantz
}

Heated tobacco products (HTP) represent the latest in a long line of products tobacco companies have developed and marketed as less dangerous than conventional cigarettes, beginning with so-called 'safer cigarettes' in the 1960s. ${ }^{12}$ HTP (figure 1) heat tobacco to generate an inhaled nicotine aerosol and are marketed using messages that explicitly or implicitly claim they are safer than cigarettes. ${ }^{3-8}$

In 2018, HTP were available in many countries (table 1). In the USA, before marketing new tobacco products, the Family Smoking Prevention and Tobacco Control Act ${ }^{9}$ (FSPTCA) requires premarket review by the Food and Drug Administration (FDA) to demonstrate that marketing them would be 'appropriate for the protection of the public health' (FSPTCA sections 910 and 905(j)). Additionally, to market any new tobacco product in the USA with claims of reduced risk or reduced exposure to toxins compared to other tobacco products ('Modified Risk Tobacco Product'; MRTP), the company must first obtain an MRTP marketing order from the FDA. In December 2016, Philip Morris International (PMI) submitted an application to market IQOS, one of its HTP, with MRTP claims. ${ }^{10}$ PMI's MRTP application included extensive details about the product, the chemistry of the aerosol it produces, related toxicology, effects on clinical measures in people, perceptions of the product and its packaging (including warning labels), and behavioural factors. This application sought FDA approval of PMI's claims that smokers who switched completely to IQOS would reduce their health risks or exposure to dangerous substances compared with smoking cigarettes.

As of November 2017, there were 31 studies of HTP published in the peer reviewed literature, 20 of which were affiliated with the tobacco industry. ${ }^{11}$ The 11 independent studies focused on awareness, use, and secondhand emissions of HTP, while the industry affiliated papers examined nicotine delivery and mainstream emissions and exposures to selected toxicants. The fact that the literature has been dominated by industry is particularly concerning because tobacco companies have a record of publishing incomplete or manipulated information and presenting it to governments. ${ }^{12-16}$ For example, PMI ${ }^{17-20}$ and British American Tobacco $^{21-23}$ (BAT) conducted and published studies arguing that additives did not increase cigarettes' toxicities. However, internal PMI documents and analysis of PMI's data done by people independent of the tobacco industry revealed that many toxicants increased when additives-notably menthol-were present. ${ }^{15}$

PMI's IQOS MRTP application (the 'application') provides an opportunity to analyse PMI's data. This supplement to Tobacco Control includes eight papers that present analyses of PMI's application by researchers independent of the tobacco industry and 12 papers that provide independent assessments of HTP effects, including their political and policy implications. Together, these papers provide insights into IQOS (and, in broad terms, other HTP) and support the January 2018 vote by the FDA Tobacco Product Scientific Advisory Committee that PMI's application did not demonstrate it reduced risk claims for IQOS $^{24}$ (online supplementary table S1). These papers also put HTP in the overall context of the tobacco companies' plans to maintain and grow their markets in the future and outline regulatory responses.

\section{HEALTH EFFECTS}

The fundamental justification for introducing HTP is the claim that they are substantially less dangerous than conventional cigarettes. PMI's application includes PMI's 3-month study of 24 non-cancer biomarkers of potential harm (BOPH) in humans using IQOS compared with conventional cigarettes. These biomarkers include measures of inflammation, oxidative stress, cholesterol and triglycerides, blood pressure, and lung function. (PMI did separate studies of biomarkers of exposure, several of which are carcinogens.) While PMI's application emphasises that these biomarkers generally changed in positive directions, Glantz's ${ }^{25}$ examination of the data revealed no statistically detectable difference between IQOS and conventional cigarettes for 23 of the $24 \mathrm{BOPH}$ in Americans and 10 of 13 in Japanese. Moreover, it is likely that the few significant differences were false positives. Thus, despite delivering lower levels of some toxicants, PMI's own data fail to show consistently lower risks of harm in humans using IQOS compared with conventional cigarettes.

In June, 2018 PMI issued a press release ${ }^{26}$ announcing that a 6-month human study comparing IQOS with conventional cigarettes found eight biomarkers improved in those who switched to IQOS. PMI did not provide specific results. In contrast to the application, PMI's new study only examined six BOPH (plus two biomarkers of exposure). Further, PMI did not report the full range of biomarkers used in the earlier study although they can be measured in a blood sample or simple physiological test. This additional study raises questions about PMI manipulating the experimental design or data analysis as it and other companies have a history of doing. ${ }^{15}$

While HTP are presented as 'new', they are simply the latest incarnation of a technology tobacco companies have been developing for decades. Elias et $a l^{2}$ analysed previously secret PMI documents, public communications and the 
A

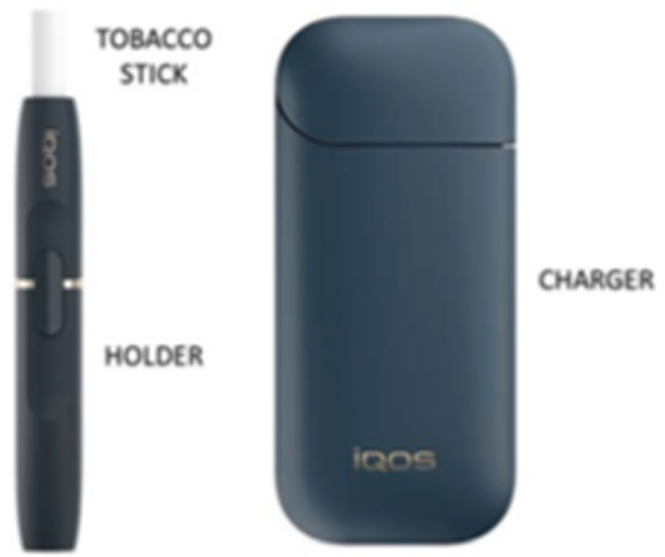

B

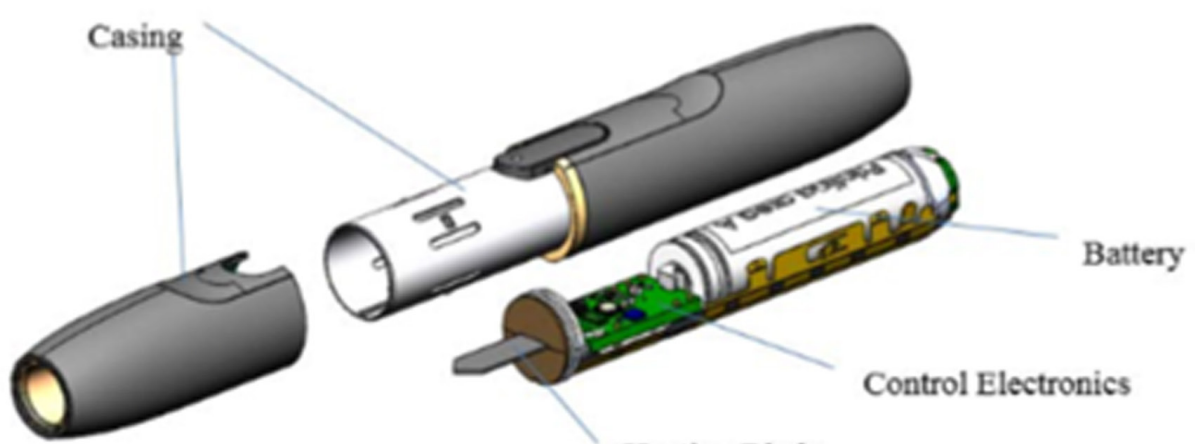

Heating Blade

C

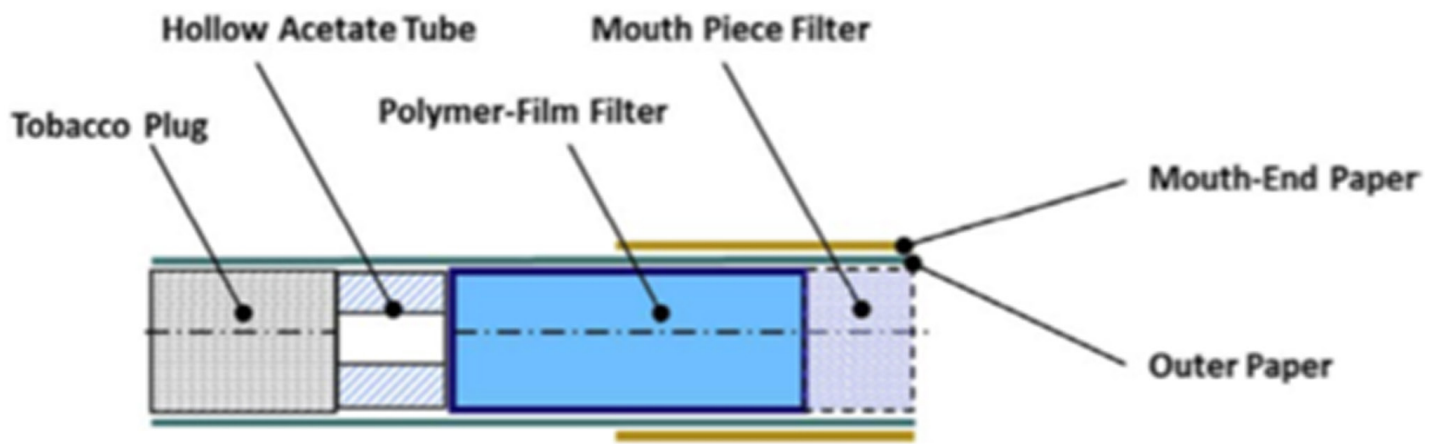

Figure 1 (A) The Philip Morris International IQOS charger, holder and HeetStick (tobacco stick). (B) Schematic drawing of holder. (C) Schematic of HeetStick tobacco stick. ${ }^{10}$

application to compare IQOS to Accord, an earlier HTP that PMI unsuccessfully marketed in the USA and Japan in 1998 and 2006, respectively. PMI's public statements seemed contradictory, claiming that Accord reduced exposure to harmful constituents while consistently emphasising that the reductions did not mean Accord was safer than conventional cigarettes. In terms of aerosol chemistry, Accord had lower levels than IQOS of some toxicants and higher levels of others. PMI appears to be capitalising on the MRTP process to make reduced exposure claims for IQOS despite the fact that overall toxicant exposures are not, on average, different than Accord.
Discussion of HTP (as well as e-cigarettes) has focused on cancer even though cardiovascular and metabolic disease kill about as many smokers as cancer. ${ }^{27}$ Unlike cancer, the dose-response relationship for cardiovascular effects is highly non-linear, with large effects at low doses. ${ }^{28}$ An important pathway through which tobacco use increases the risk of heart disease is by impairing the ability of arteries to enlarge when needed to accommodate increases in blood flow (flow mediated dilation, FMD). Nabavizadeh et $a l^{29}$ tested whether exposure to IQOS aerosol impaired FMD in a well-established experimental model in which rats inhale IQOS aerosol from a single 
Table 1 Availability of heated tobacco product by major cigarette company and country of availability (January 2018)

\begin{tabular}{|c|c|c|c|}
\hline Company & Product & Year launched & Countries/comments \\
\hline British American Tobacco & $\begin{array}{l}\text { iFuse* } \\
\text { glo }\end{array}$ & $\begin{array}{l}2015 \\
2016\end{array}$ & Romania, Japan, Switzerland, Canada, South Korea, Russia. \\
\hline $\begin{array}{l}\text { China National Tobacco Corporation/State } \\
\text { Tobacco Monopoly Administration (STMA) }\end{array}$ & Not reported & Not launched & $\begin{array}{l}\text { A few of the companies claim to have over } 30 \text { patents of HTP and } \\
\text { continue to be engaged in research and development of these } \\
\text { products. But none yet are in the market. }\end{array}$ \\
\hline Imperial Brands & Not reported & Not launched & $\begin{array}{l}\text { Focusing on e-cigarettes at the moment, claims to have options to } \\
\text { launch when it deems that time is right. }\end{array}$ \\
\hline Japan Tobacco International & Ploom TECH $†$ & 2016 & Japan, Switzerland. \\
\hline KT\&G Corp & lil & 2017 & South Korea \\
\hline Philip Morris Internationalł & $\begin{array}{l}\text { IQOS } \\
\text { TEEPS§ }\end{array}$ & $\begin{array}{l}2014 \\
\text { Not yet launched }\end{array}$ & $\begin{array}{l}\text { Canada, Guatemala, Colombia, Czech Republic, Denmark, France, } \\
\text { Germany, Greece, Israel, Italy, Kazakhstan, Lithuania, Monaco, } \\
\text { Netherlands, Poland, Portugal, Romania, Russia, Serbia, Slovak } \\
\text { Republic, Slovenia, Spain, Switzerland, Ukraine, United Kingdom, } \\
\text { South Africa, South Korea, Japan, New Zealand. }\end{array}$ \\
\hline
\end{tabular}

Source: Bialous and Glantz. ${ }^{49}$

* It is unclear that iFuse will remain in the market in Romania, where glo was introduced in 2018.

†Ploom TECH is described as a hybrid between an HTP and a vaporiser. It is to be used with Mevius capsules. Mevius is one of JTI's best-selling cigarette brands. The capsules contain tobacco that are then heated by vapour.

$\ddagger$ PMI website states that it is developing a new heated nicotine delivery product that has no tobacco, STEEM, among other 'reduced risk' products.

§We do not know what TEEPS stands for, it is not included in the product's description (https://www.pmi.com/smoke-free-products/teeps-carbon-heated-tobacco-product).

HTP, heated tobacco product; JTI, Japan Tobacco International;PMI, Philip Morris International.

HeetStick (the IQOS tobacco stick), mainstream smoke from a single Marlboro Red cigarette, or clean air. In contrast with PMI's application claiming that IQOS causes less impairment than conventional cigarettes, Nabavizadeh et $a^{29}$ showed IQOS aerosol's acute effects impaired vascular endothelial function (measured with FMD) comparably with cigarette smoke.

Moazed $e t a l^{30}$ found data in PMI's application raising significant concerns about IQOS' pulmonary effects. Rats exposed to IQOS suffered pulmonary inflammation and immunomodulation. Although PMI did not report any direct measures of pulmonary inflammation in humans, they measured pulmonary function and found no evidence of improvement in cigarette smokers who switched to IQOS. PMI's application also ignores the effect of dual use and secondhand aerosol exposure.

Independent research confirmed adverse effects of IQOS aerosol on lung cells. Leigh $e t$ al $l^{31}$ exposed human bronchial epithelial cells in vitro to aerosols from three PMI products: IQOS (tobacco flavour), an e-cigarette (MarkTen, tobacco flavour) and a conventional cigarette (Marlboro Red) at comparable nicotine levels at the air-liquid interface. IQOS showed significantly higher cytotoxicity than e-cigarettes, but less than combustible cigarettes. These observations have important legal implications in the USA because to authorise marketing IQOS with reduced risk claims, the FDA would have to find that IQOS would benefit the public health and significantly reduce harm or reduce exposure to harmful substances 'compared to the similar types of tobacco products then on the market' (FSPTCA section 911(g)(2)(B)(ii)), and e-cigarettes were currently on the market at the time that PMI submitted its application.

Reinforcing the need to compare HTP to e-cigarettes rather than cigarettes, Leigh $e t a l^{32}$ compared the levels of carcinogenic tobacco specific nitrosamines (TSNA) in IQOS aerosols to MarkTen e-cigarettes and Marlboro Red 100 conventional cigarettes at comparable nicotine delivery levels. TSNA yields per puff in IQOS aerosol was an order of magnitude lower than in Marlboro cigarette smoke, but an order of magnitude higher than in MarkTen e-cigarettes. In short, IQOS does not reduce exposure to these important carcinogens nearly as much as e-cigarettes.
Most discussion of the toxicants in non-cigarette tobacco products compare them to cigarettes on the assumption that if the non-cigarette products deliver lower levels of toxicants than cigarettes, the products would be less dangerous. However, St Helen $e t a l^{33}$ found that PMI's data only support its claim that IQOS reduces exposure to some (40 of 93) harmful and potentially harmful constituents (HPHCs) identified by the FDA. PMI's data also show significantly higher levels of many toxicants not on the FDA HPHC list in IQOS aerosol compared with cigarette smoke, with 22 over twice as high and 7 over 10 times higher. Therefore, it is important to expand chemical assessment of emissions from HTP and other new tobacco products beyond those found in cigarette smoke.

It is possible that HTP could cause some diseases not caused by conventional cigarettes. Chun $e t a l^{34}$ identified animal and human studies in PMI's application suggesting that IQOS may cause liver toxicity not observed in cigarette users. PMI compared liver toxicity in rats exposed to IQOS or cigarette smoke, and found that several measures of liver toxicity (liver weights, blood levels of alanine aminotransferase and hepatocellular vacuolisation) increased more in female (but not male) rats exposed to IQOS than cigarettes. PMI's human clinical data also suggested the possibility of increased liver injury in one of their studies: following 5 days of using IQOS, conventional cigarettes, or smoking abstinence, plasma bilirubin was higher in IQOS users than conventional smokers or abstainers. PMI Science posted a response to this paper on its website stating that "based on an analysis of our toxicological studies and clinical studies performed according to international standards of good practice, there is no evidence that IQOS use leads to hepatotoxicity [emphasis added]. ${ }^{35}$ In contrast to this unequivocal statement, the point that Chun et al make is not that the data PMI submitted to the FDA prove hepatotoxicity, but that the combination of animal data and some of the human data constitute a pattern worth careful consideration, especially in light of the short duration of the studies and lack of additional potential insults to the liver including alcohol use and other drug use that is common in smokers. 
IQOS (and likely HTP generally) are simply different from conventional cigarettes and deliver less of some toxicants and more of others, so that IQOS may pose lower, the same or higher health risks than cigarettes depending on the disease. IQOS emits more of several important toxins with more adverse health effects than e-cigarettes.

\section{PERCEPTIONS OF THE PRODUCT AND WARNING LABELS}

Despite the evidence discussed above, in 2018 IQOS and other HTP were being marketed around the world with claims that they are less harmful than cigarettes because they expose users to lower levels of some toxicants. Popova et $a l^{36}$ examined the qualitative and quantitative Perception and Behavior Assessment Studies in PMI's application which revealed that consumers perceive even reduced exposure claims as reduced risk claims. Allowing PMI to promote IQOS with reduced exposure claims would amount to permitting the kind of 'light' and 'mild' fraud that the FSPTCA and WHO Framework Convention on Tobacco Control (FCTC) expressly prohibit for other tobacco products.

This misunderstanding of reduced exposure as reduced risk bears directly on how IQOS should be labelled so as not to mislead consumers. McKelvey et $a l^{37}$ examined PMI's application focusing on the statements that switching completely from cigarettes to IQOS reduces risk. PMI failed to demonstrate that current smokers will understand what 'switching completely' means, and therefore failed to demonstrate that their IQOS will not decrease smokers' intentions to quit smoking, or that IQOS users will 'switch completely' (PMI's other studies showed most people use IQOS and cigarettes concurrently, so-called dual users.) Additionally, PMI's study design and measurement instruments suffered design flaws, and their reporting of associated findings is misleading. Experience with other products such as e-cigarettes suggests consumers will not understand that they must completely quit smoking cigarettes to achieve the claimed health benefits of IQOS. Rather, consumers will likely misunderstand unsupported claims of reduced risks to mean IQOS are risk-free.

Independently confirming PMI's results, El-Toukhy et al ${ }^{38}$ examined the impact of reduced exposure and reduced harm MRTP claims in a national sample of US adults and adolescents. They found that communicating lower risk in MRTP claims led to lower perceived risk among adults and adolescents and increased the likelihood that adults would use the product. Reduced exposure claims led to lower perceived chemical quantity and lower perceived risk, but had no effect on likelihood of product use. Adults and adolescents misinterpreted reduced exposure claims as communicating lower risk, even when no explicit reduced risk claims were made. Because reduced exposure MRTP claims are not permissible under US law if they mislead the public to believe the product presents less risk of harm, these studies demonstrate that reduced exposure claims for IQOS are impermissible.

These concerns are particularly acute for adolescents who are susceptible to using novel tobacco products. E-cigarettes provide a cautionary tale for any new tobacco product coming to market: e-cigarettes have attracted youth at low risk of initiating nicotine use with cigarettes, ${ }^{39}$ many of whom then proceed to cigarettes. ${ }^{40}$ McKelvey et $a l^{41}$ found that PMI's application failed to provide any evidence regarding the effect IQOS and its marketing will have on the likelihood that adolescents who are not tobacco users or who are former tobacco users will start nicotine use with IQOS. Instead, PMI conducted studies of adults that relied on 'behavioural intention' as a proxy to predict IQOS use, ignoring evidence that these models do not accurately predict tobacco use. Of added concern, the IQOS name, packaging and retail shops resemble popular cell phones that attract youth. ${ }^{42}$ PMI's data and independent scientific studies regarding novel tobacco products (including e-cigarettes) marketing suggest IQOS will attract adolescent and young adult non-users to initiate tobacco use with IQOS and could also increase polyuse of different tobacco products.

Hair et $a l^{43}$ examined IQOS marketing in Japan and Switzerland and studied consumer perceptions, attitudes and behaviours. Expert interviews and IQOS packaging and marketing analyses revealed that IQOS was marketed as a clean, chic and pure product which resonated in cultures that value cleanliness, exclusivity and high-tech appearances. Japanese consumers used IQOS for socialising with non-smokers. Focus group participants in both Japan and Switzerland reported lower levels of satisfaction with IQOS than cigarettes, although many found the packaging appealing. Few participants reported potential health benefits compared with cigarettes.

PMI introduced IQOS to Korea in May 2017. Three months later, Kim et $a l^{44}$ conducted an online survey of young adults including current, ever and non-users. Rather than switching from conventional cigarettes to IQOS, all current IQOS users continued to use cigarettes or e-cigarettes. There were no IQOS-only users. Current users believed IQOS less harmful or useful to stop smoking. The observation that all the current IQOS users were dual users of conventional cigarettes or e-cigarettes contradicts PMI's assumption that cigarette smokers would switch to HTP.

As of July 2018, the FDA had not authorised HTP for sale in the USA, but awareness and use were increasing. Nyman et $a l^{45}$ assessed awareness and use of HTP in the USA. From 2016 to 2017, adult awareness of HTP increased from 9.3\% to $12.4 \%$, ever use increased from $1.4 \%$ to $2.2 \%$ and current use doubled from $0.5 \%$ to $1.1 \%$. Non-white adults, cigarette smokers, and both current and former users of e-cigarettes were more likely to use HTP.

\section{POLICY, POLITICS AND LAW}

Tobacco companies have promoted 'harm reduction' for decades. Although tobacco harm reduction proponents take British psychologist Michael Russell's 1976 idea that 'people smoke for nicotine but they die from the tar' ${ }^{46}$ as an article of faith, he simply presented it as a 'hypothesis'. Elias and Ling ${ }^{47}$ examined tobacco industry documents and found that Russell collaborated with BAT on two 'safer cigarette' studies and received $£ 55000$ ( $£ 300850$ or $\$ 398000$ in 2018 ) to study medium-nicotine low-tar cigarettes. The most prominent early HTP was RJ Reynolds' (RJR) Premier, introduced in the USA in 1988. Russell engaged extensively with RJR about Premier's 'positive aspects' and published an unsigned 1991 Lancet editorial ${ }^{48}$ endorsing Premier as a 'near-perfect low tar cigarette' 2 years after RJR stopped marketing Premier without disclosing his conflict of interest. Although Premier failed, RJR saw future business opportunities for novel products if endorsed by health authorities, making conflicts of interest highly important considerations in assessing product endorsements, including those published by high-impact medical journals.

It is important to consider HTP in the context of multinational tobacco companies' product mix and response to the tightening regulatory environment promoted by FCTC. Bialous and Glantz ${ }^{49}$ describe how HTP extend the industry's strategies to undermine government regulation by reframing tobacco companies from part of the problem to part of the solution. Under the 'harm reduction' moniker, companies are attempting 
to rehabilitate their reputations to more effectively influence governments to roll back existing tobacco control policies or create exemptions for HTP. Where regulations are absent or loopholes exempt HTP from existing regulations, companies' market HTP to increase social acceptability for all their tobacco products. Governments must ensure that HTP are regulated or banned, and reject partnerships with tobacco companies to promote 'harm reduction'. Doing so requires governments in countries where HTP are not available to keep them out or, if allowed in the market, strictly regulate them under the FCTC.

Israel illustrates how PMI took advantage of regulatory ambiguity to implement an aggressive campaign promoting IQOS as safer than conventional cigarettes. Rosen and Kislev ${ }^{50}$ describe how PMI promoted IQOS as part of its 'Smoke-Free Israel vision' after launching IQOS in December 2016. The campaign began with quiet pre-market meetings with government officials, followed by meetings in Israel's Parliament and an intense campaign in the printed press to promote harm reduction and PMI's 'Smoke-Free Israel vision'. The public campaign included digital and print marketing aimed at young people to promote PMI's 'Smoke-Free Israel vision' and harm reduction using the theme 'IQOS Changes Everything', that stressed IQOS was clean with less smell and no ash. PMI's campaign initially resulted in IQOS' exemption from tobacco regulations. These policies were later reversed after three petitions to the Supreme Court, pressure from health organisations and leading politicians, and wide press coverage of PMI's influence on Parliament's decision-making process. Israel's weak and poorly enforced advertising restrictions, however, have allowed PMI to continue its marketing claims.

In determining whether any new tobacco product may be sold, including HTP, the FDA must consider the product's overall population health impact. Importantly, in addition to any changes in specific toxicity for current smokers who switch from cigarettes to HTP, the availability of HTP affects nicotine and cigarette initiation and cessation. For products that have not been on the market to empirically answer these questions, modelling is an important element of the decision-making process. Max et $a l^{51}$ evaluated PMI's Population Health Impact Model (PHIM), as used in its application, in comparison with other available models. Although similar to many published models, PHIM includes assumptions likely to lead to a positive assessment of IQOS' population health impact. PHIM does not consider impacts on morbidity, underestimates mortality, does not include impacts on non-users, ignores the impact of IQOS on nicotine product initiation among never smokers and does not use the latest US data to set the model's parameters. Because PHIM systematically underestimates the impact of IQOS on the population as a whole, it cannot adequately justify marketing IQOS as 'appropriate to protect public health'.

The most important change in the policy environment since the tobacco companies were last actively promoting HTP in the 1980 s and 1990s is the advent of formal regulatory regimes for tobacco products through the FSPTCA in the USA and the FCTC globally. Lempert and Glantz ${ }^{52}$ analysed laws and obligations that apply to the introduction, labelling and marketing of IQOS under FSPTCA and FCTC. PMI's premarket tobacco application and MRTP application for IQOS do not meet FSPTCA requirements on reduced harm or net public health benefit. The FDA can only authorise sale of new products through the new tobacco product pathway that are better for public health than products currently on the market, and e-cigarettes, currently sold in the USA, should probably be the comparator product. FCTC obligates parties to implement laws to reduce tobacco use and nicotine addiction, and the introduction of any new tobacco product must be assessed against this goal. PMI's aggressive marketing techniques for IQOS using targeted customer interventions and sophisticated technologies to capture data and monitor use directly from the IQOS device via the internet ${ }^{53}$ should concern privacy and public health advocates. Moreover, nothing in the US law or FCTC prevents authorities from prohibiting HTP. If not banned, all HTP components should be regulated as stringently as tobacco products, including restrictions on labelling, advertising, sales to minors, price and taxation policies, and smoke-free measures, and these laws should be aggressively enforced.

\section{CONCLUSION}

HTP are the latest effort by tobacco companies to adapt to a changing regulatory landscape to maintain and expand their customer base amid declining social acceptability of tobacco use and declining cigarette consumption. IQOS and other HTP are the newest in a long string of products designed to retain customers and protect tobacco companies' reputations and political influence. Because US law required PMI to provide detailed results of their IQOS research for its MRTP application, it was possible to independently assess their research. PMI's own data do not support its claims that IQOS is less dangerous than cigarettes. While IQOS may expose users to lower levels of some toxicants than cigarettes, they also expose users to higher levels of other toxicants. Likewise, IQOS likely exposes users to lower risks of some diseases and higher risks of others. PMI's research, confirmed by independent research, also highlights the fact that reduced exposure claims are misunderstood as reduced harm claims. These facts raise serious concerns that HTP and their marketing will harm youth and young adults and undermine cessation among smokers without providing health benefits to smokers who use them.

Fortunately, regulatory tools are in place to make rational, evidence-based decisions about these products. The question is whether public health advocates will ensure that policy-makers prioritise protecting public health and prevent tobacco companies from again using their extensive public relations and political resources to avoid regulation and protect profits. Policy makers should give greater weight to the advice provided by public health scientists than to submissions from industry when it comes to regulating tobacco products such as HTP.

Acknowledgements The author thanks the authors of the other papers in this supplement to Tobacco Control for their feedback on this paper and Lauren Lempert and Stella Bialous for assistance in shortening it.

Contributors SAG is the sole author of this paper.

Funding This work was supported by the US National Cancer Institute and Food and Drug Administration Center for Tobacco Products (P50 CA180890).

Disclaimer The content is solely the responsibility of the author and does not necessarily represent the official views of the National Institutes of Health or the FDA. The funding agencies played no role in design and conduct of the study; collection, management, analysis and interpretation of the data; preparation, review or approval of the manuscript; or decision to submit the manuscript for publication.

Competing interests None declared.

Patient consent Not required.

Provenance and peer review Commissioned; internally peer reviewed.

Open access This is an open access article distributed in accordance with the Creative Commons Attribution Non Commercial (CC BY-NC 4.0) license, which permits others to distribute, remix, adapt, build upon this work non-commercially, and license their derivative works on different terms, provided the original work is 
properly cited, appropriate credit is given, any changes made indicated, and the use is non-commercial. See: http://creativecommons.org/licenses/by-nc/4.0/.

\section{REFERENCES}

1 Glantz SA, Barnes DE, Bero L, et al. The Cigarette Papers. Chapter 4: The Search for a "Safe" Cigarette. Berkeley, CA: University of California Press, 1996.

2 Elias J, Dutra LM, G SH, et al. Revolution or redux? assessing IQOS through a precursor product. Tob Control 2018:tobaccocontrol-2018-054327.

3 Tobacco J, 2017. Japan JT will launch ploom tech in the tokyo metropolitan area from end of June 2017. https://www.jt.com/media/news/2017/0523_01.html

4 Westra N, Hodgart K, 2017. Tobacco giant: 'Tide Turning' on smoke-free products in asia. http://www.atimes.com/article/tobacco-giant-tide-turning-smoke-free-productsasia/ (accessed 25 Jun 2018).

5 González M, 2017. Costa rica iqos: El nuevo concepto del cigarro del futuro. https:// www.laprensalibre.cr/Noticias/detalle/94689/iqos:-el-nuevo-concepto-del-cigarro-delfuturo (accessed 25 Jun 2018).

6 Tobacco BA, Geographic expansion of GI continues with launch in Russia. BAT 2017. http://www.bat.com/group/sites/UK__9D9KCY.nsf/vwPagesWebLive/DOASAEHC (accessed 25 Jun 2018)

7 Philip Morris International. Switzerland philip morris international to build smoke-free product facility in Germany. Another Step Towards a Smoke-Free Future 2017 https:// www.businesswire.com/news/home/20170619005644/en/Philip-Morris-InternationalBuild-Smoke-Free-Product-Facility (accessed 25 Jun 2018).

8 Philip Morris International, 2018. Alternatives to smoking: Our smoke-free products. https://www.pmi.com/smoke-free-products?utm_expid=.Lc8-1iT_RhifJZOhRCQSrQ.0\& utm_referrer=https $\% 3 \mathrm{~A} \% 2 \mathrm{~F} \% 2 \mathrm{Fwww}$.pmi.com $\% 2$ Fsmoke-free-products $\% 2$ Fiqosour-tobacco-heating-system (accessed 10 Jan 2018).

9 Family Smoking Prevention and Tobacco Control Act (Fsptca, Pub. L. 111-31, 21 U.S.C. 387 Et Seq), 2009.

10 FDA. Philip morris products S.A. Modified Risk Tobacco Product (Mrtp) applications. Https://Www.Fda.Gov/Tobaccoproducts/Labeling/Marketingandadvertising/ Ucm546281.Htm (accessed 13 May 2018).

11 Simonavicius E, McNeill A, Shahab L, et al. Heat-not-burn tobacco products: a systematic literature review. Tob Control 2018;:tobaccocontrol-2018-054419--2010.

12 Neilsen K, Glantz SA. A tobacco industry study of airline cabin air quality: dropping inconvenient findings. Tob Control 2004;13(Suppl 1):20i-9.

13 Barnes RL, Hammond SK, Glantz SA. The tobacco industry's role in the 16 Cities Study of secondhand tobacco smoke: do the data support the stated conclusions? Environ Health Perspect 2006;114:1890-7.

14 Barnes RL, Glantz SA. Endotoxins in tobacco smoke: shifting tobacco industry positions. Nicotine Tob Res 2007:9:995-1004.

15 Wertz MS, Kyriss T, Paranjape S, et al. The toxic effects of cigarette additives. Philip Morris' project mix reconsidered: an analysis of documents released through litigation. PLoS Med 2011;8:e1001145

16 Velicer C, Aguinaga-Bialous S, Glantz S. Tobacco companies' efforts to undermine ingredient disclosure: the Massachusetts benchmark study. Tob Control 2016;25:575-83.

17 Carmines EL. Evaluation of the potential effects of ingredients added to cigarettes. Part 1: cigarette design, testing approach, and review of results. Food Chem Toxicol 2002:40:77-91.

18 Roemer E, Tewes FJ, Meisgen TJ, et al. Evaluation of the potential effects of ingredients added to cigarettes. Part 3: in vitro genotoxicity and cytotoxicity. Food Chem Toxicol 2002;40:105-11.

19 Vanscheeuwijck PM, Teredesai A, Terpstra PM, et al. Evaluation of the potential effects of ingredients added to cigarettes. Part 4: subchronic inhalation toxicity. Food Chem Toxicol 2002;40:113-31.

20 Rustemeier K, Stabbert R, Haussmann HJ, et al. Evaluation of the potential effects of ingredients added to cigarettes. Part 2: chemical composition of mainstream smoke. Food Chem Toxicol 2002:40:93-104.

21 Baker RR, Massey ED, Smith G. An overview of the effects of tobacco ingredients on smoke chemistry and toxicity. Food Chem Toxicol 2004;42 Suppl:53-83.

22 Baker RR, Pereira da Silva JR, Smith G. The effect of tobacco ingredients on smoke chemistry. Part I: Flavourings and additives. Food Chem Toxicol 2004;42 Suppl:3-37.

23 Baker RR, Pereira da Silva JR, Smith G. The effect of tobacco ingredients on smoke chemistry. Part II: casing ingredients. Food Chem Toxicol 2004;42 Suppl:39-52.

24 Food and Drug Administration, 2018. Tpsac meeting materials and information. Transcript Day 2. 2018 https://www.fda.gov/downloads/AdvisoryCommittees/Comm itteesMeetingMaterials/TobaccoProductsScientificAdvisoryCommittee/UCM599235. pdf (accessed 3 Apr 2018).
25 Glantz SA. PMI's own in vivo clinical data on biomarkers of potential harm in Americans show that IQOS is not detectably different from conventional cigarettes. Tob Control 2018;27(Suppl1):s9-s12.

26 Philip Morris International. Philip Morris (PM) Announces positive results from new clinical study on IQOS. $2018 \mathrm{https}$ ://www.streetinsider.com/dr/news.php?id= 14312015 (accessed 21 June 2018).

27 US Department of Health and Human Services, Rockville, MD the health consequences of smoking - 50 years of progress. A report of the surgeon general. Executive Summary 2014. https://www.surgeongeneral.gov/library/reports/50-years-of-progress/ index.html (accessed 17 Jul 2018).

28 Barnoya J, Glantz SA. Cardiovascular effects of second-hand smoke help explain the benefits of smoke-free legislation on heart disease burden. $J$ Cardiovasc Nurs 2006:21:457-62

29 Nabavizadeh P, Liu J, Havel CM, et al. Vascular endothelial function is impaired by aerosol from a single IQOS HeatStick to the same extent as by cigarette smoke. Tob Control 2018;27(Suppl1):s13-s19.

30 Moazed F, Chun L, Matthay MA, et al. Assessment of industry data on pulmonary and immunosuppressive effects of IQOS. Tob Control 2018;27(Suppl1):s20-s25.

31 Leigh NJ, Tran PL, O'Connor RJ, et al. Cytotoxic effects of heated tobacco products (HTP) on human bronchial epithelial cells. Tob Control 2018;27(Suppl1):s26-s29.

32 Leigh NJ, Palumbo MN, Marino AM, et al. Tobacco-specific nitrosamines (TSNA) in heated tobacco product IQOS. Tob Control 2018;27(Suppl1):s37-s38.

33 St Helen G, Jacob lii P, Nardone N, et al. IQOS: examination of Philip Morris International's claim of reduced exposure. Tob Contro/ 2018:27(Suppl1):s30-s36.

34 Chun L, Moazed F, Matthay M, et al. Possible hepatotoxicity of IQOS. Tob Control 2018:27(Suppl1):s39-s40.

35 Baker G, Picavet P, Smiith M, et al, 2018. Summary of Evidence on the Absence of Hepatotoxicity of IQOS: Response to the Article Entitled "Possible Hepatotoxicity of IQOS" by Chun Et Al., 2018 (PMI Science) https://www.pmiscience.com/discover/ news/summary-of-evidence-on-the-absence-of-hepatotoxicity-of-iqos-response (accessed 23 Sep 2018).

36 Popova L, Lempert LK, Glantz SA. Light and mild redux: heated tobacco products' reduced exposure claims are likely to be misunderstood as reduced risk claims. Tob Control 2018;27(Suppl1):s87-s95.

37 McKelvey K, Popova L, Kim M, et al. IQOS labelling will mislead consumers. Tob Control 2018;27(Suppl1):s48-s54.

38 El-Toukhy S, Baig SA, Jeong M, et al. Impact of modified risk tobacco product claims on beliefs of US adults and adolescents. Tob Control 2018;27(Suppl1):s62-s69.

39 Dutra LM, Glantz SA. E-cigarettes and National Adolescent Cigarette Use: 2004-2014 Pediatrics 2017;139:139.

40 Soneji SS, Sung HY, Primack BA, et al. Quantifying population-level health benefits and harms of e-cigarette use in the United States. PLoS One 2018;13:e0193328.

41 McKelvey K, Popova L, Kim M, et al. Heated Tobacco Products Likely Appeal to Adolescents and Young Adults. Tob Control 2018:27(Suppl1):s41-s47.

42 Kim M. Philip Morris International introduces new heat-not-burn product, IQOS, in South Korea. Tob Control 2018;27:e76-e78.

43 Hair EC, Bennett M, Sheen E, et al. Examining perceptions about IQOS heated tobacco product: consumer studies in Japan and Switzerland. Tob Control 2018;27(Suppl1):s70-s73.

$44 \mathrm{Kim} \mathrm{J}, \mathrm{Yu} \mathrm{H}$, Lee S, et al. Awareness, experience and prevalence of heated tobacco product, IQOS, among young Korean adults. Tob Control 2018;27(Suppl1):s74-s77.

45 Nyman AL, Weaver SR, Popova L, et al. Awareness and use of heated tobacco products among US adults, 2016-2017. Tob Control 2018;27(Suppl1):s55-s61.

46 Russell MA. Low-tar medium-nicotine cigarettes: a new approach to safer smoking. Br Med J 1976:1(6023):1430-3.

47 Elias J, Ling PM. Invisible smoke: third-party endorsement and the resurrection of heat-not-burn tobacco products. Tob Control 2018:27(Suppl1):s96-s101.

48 The Lancet. Nicotine use after the year 2000. Lancet 1991;337:1191-2.

49 Bialous SA, Glantz SA. Heated tobacco products: another tobacco industry global strategy to slow progress in tobacco control. Tob Control 2018:27(Supp|1):s111-s117.

50 Rosen L, Kislev S. The IQOS campaign in Israel. Tob Control 2018;27(Suppl1):s78-s81.

51 Max WB, Sung HY, Lightwood J, et al. Modelling the impact of a new tobacco product: review of Philip Morris International's Population Health Impact Model as applied to the IQOS heated tobacco product. Tob Control 2018;27(Suppl1):S82-s86.

52 Lempert LK, Glantz SA. Heated tobacco product regulation under US law and the FCTC. Tob Control 2018;27(Suppl1):s118-s25.

53 Connolly G. A reduced risk nicotine delivery device or a device to enhance and contro abuse (addiction) potential through manipulation of the pattern of nicotine delivery? 2018 https://www.fda.gov/Downloads/Advisorycommittees/Committeesmeetingmat erials/Tobaccoproductsscientificadvisorycommittee/Ucm594333.Pdf (accessed 15 Feb 2018) 